\title{
A rare case of atrioventricular block
}

\author{
R. Eerdekens · L. M. Rademakers
}

Accepted: 3 May 2021 / Published online: 8 June 2021

(C) The Author(s) 2021

A previously healthy 57-year-old male presented at the emergency department (ED) with sudden onset of dizziness followed by nausea. Episodes lasted for approximately $10 \mathrm{~min}$ and resolved spontaneously. At the ED, while the patient was asymptomatic, clinical (including neurological) examination, laboratory test, electrocardiogram and echocardiography were normal. He suddenly experienced dizziness while the electrocardiogram showed sinus rhythm with 2:1 atrioventricular (AV) block (Fig. 1). The patient was diagnosed with symptomatic Mobitz type II AV block and was admitted for pacemaker implantation. On the ward he again experienced dizziness but now accompanied by neurological symptoms, i.e. ataxia, nystagmus, miosis and ptosis. Urgent cerebral computed tomography angiography showed an acute occlusion of the left-sided posterior inferior cerebellar artery (PICA) (Fig. 2). He was treated with thrombolysis, recovered well and AV block was not recorded anymore. Thereafter, magnetic resonance imaging (Fig. 3) revealed a large infarcted area related to the PICA.

Conduction disturbances, caused by autonomic dysregulation, are uncommon during acute ischaemic stroke, but can be seen in lateral medullary syndrome (Wallenberg or PICA syndrome) [1, 2].

Conflict of interest R. Eerdekens and L.M. Rademakers declare that they have no competing interests.

Open Access This article is licensed under a Creative Commons Attribution 4.0 International License, which permits use, sharing, adaptation, distribution and reproduction in any medium or format, as long as you give appropriate credit to the original author(s) and the source, provide a link to the Creative Commons licence, and indicate if changes were made. The images or other third party material in this article are included in the article's Creative Commons licence, unless indicated otherwise in a credit line to the material. If material is not included in the article's Creative Commons licence and

Fig. 1 Electrocardiogram showing sinus rhythm with 2:1 atrioventricular block

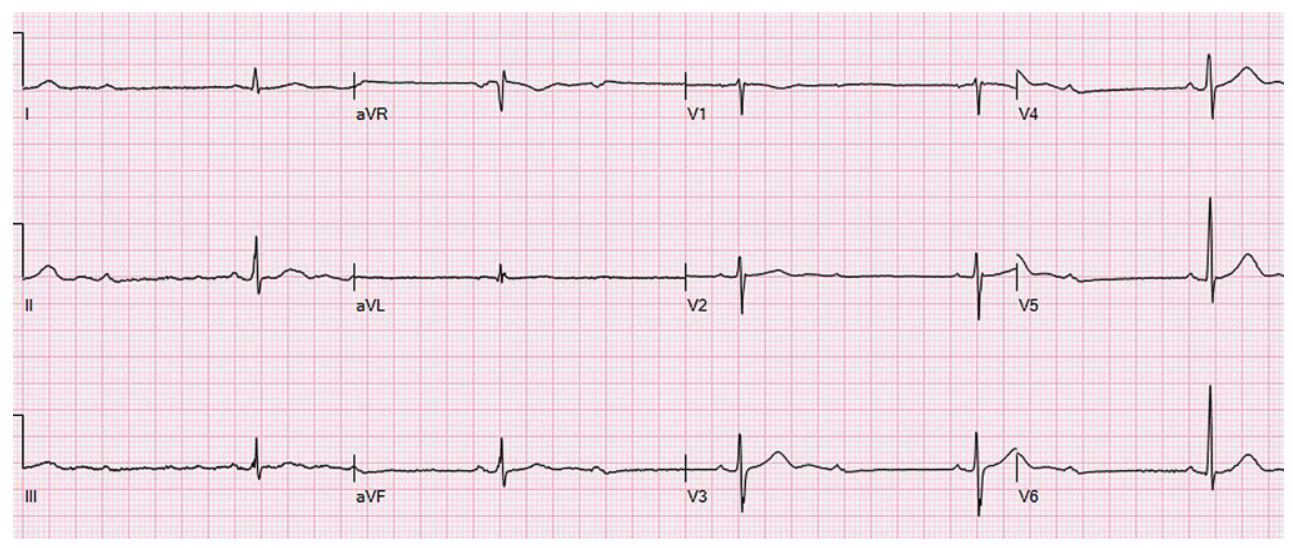

R. Eerdekens $(\bowtie) \cdot$ L. M. Rademakers

Department of Cardiology, Catharina Hospital Eindhoven,

Eindhoven, The Netherlands

rob.eerdekens@catharinaziekenhuis.nl 


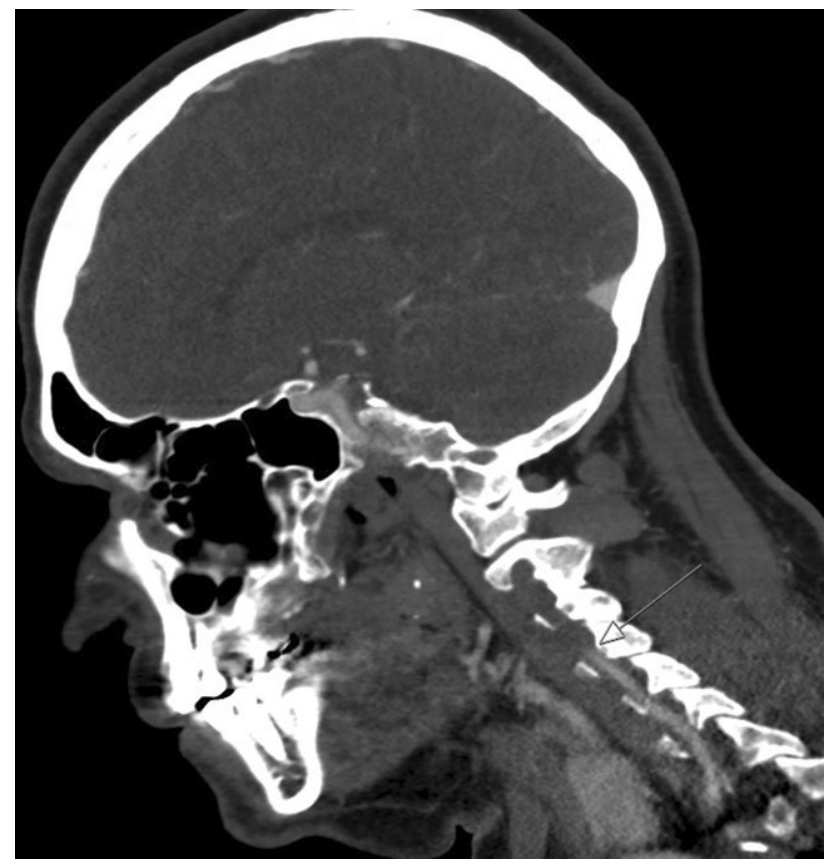

Fig. 2 Computed tomography, sagittal view. Arrow shows occluded artery

your intended use is not permitted by statutory regulation or exceeds the permitted use, you will need to obtain permission directly from the copyright holder. To view a copy of this licence, visit http://creativecommons.org/licenses/by/4.0/.

\section{References}

1. von Heinemann P, Grauer O, Schuierer G, et al. Recurrent cardiac arrest caused by lateral medulla oblongata infarction. BMJ Case Rep. 2009; https://doi.org/10.1136/bcr.02. 2009.1625.

2. Hong JM, Kim TJ, Shin DH, Lee JS, Joo IS. Cardiovascular autonomic function in lateral medullary infarction. Neurol Sci. 2013;34:1963-9.

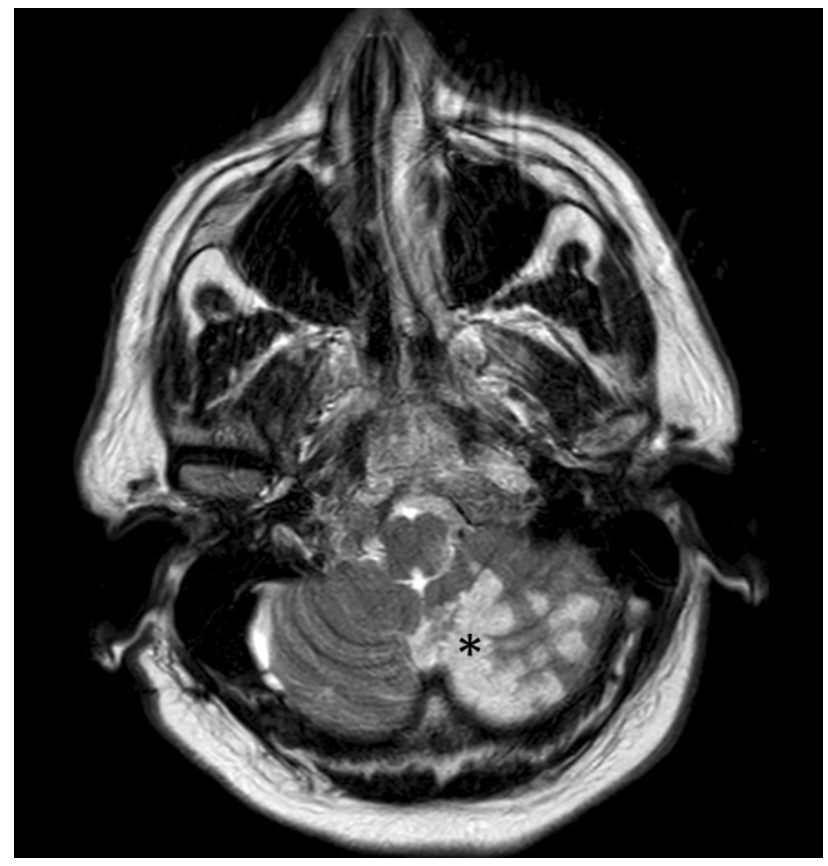

Fig. 3 T2-weighted magnetic resonance imaging showing infarcted area (asterisk) 